\title{
Electrode erosion in high power thermal arcs
}

\author{
J. Hackmann ${ }^{1}$ and H. Bebber ${ }^{2}$ \\ 1 Institute for Laser- and Plasmaphysics, University of Düsseldorf, FRG \\ 2 Mannesmann Demag AG, Duisburg, FRG
}

\begin{abstract}
The present contribution is primarily focussed on electrode erosion phenomena. A model is described for predicting electrode wear. In our model of the cathode operation we follow the arguments of Ecker ["Electrode Components of the Arc Discharge", Ergebnisse der exakten Naturwissenschaften, Vol. 23, 1961], considered to be the most successful model to date describing quantitive features.
\end{abstract}

\section{INTRODUCTION}

Electrode phenomena in electric arcs have been studied experimentally and theoretically by a number of investigators (see e.g. $/ 1 /, / 2 /$ ). The literature on cathode and anode erosion, current densities and operating properties is voluminous. Nevertheless, the design of elctrodes for high power electric arc plasma generation has been carried out almost entirely on an empirical basis. As a consequence the application of high power arcs to industrial processing is of ten accompanied by many unexpected complications, such as excessive erosion of the electrodes, uncontrollable movement of the arc plasma, etc..

\section{ELECTRODE EROSION MECHANISMS}

Carbon, tungsten and certain other refractory metals operate as cathodes with high surface temperatures at which the bulk of the observed current density can be accounted for by thermionic emission. In general the ablation of electrode material depends on the elctrode material, arc current, and species and pressure of the ambient gas. In the following we will discuss various erosion mechanisms for a tungsten cathode in an argon atmosphere at currents up to $12 \mathrm{kA}$.

\subsection{Sputtering}

In an argon arc at atmospheric pressure $10 \%$ to $15 \%$ of the current in front of the cathode is transported by the ions. The ions impinging on the metal surface can sputter metallic atoms. The sputtering yield for cold tungsten by argon ions shows fig. (1).

The ion flux on the cathode can be estimated to $1 \times 10^{22}$ ions/s. The energy of the argon ions impinging on the cathode is approximately $10 \mathrm{eV}$ (singly ionized ions, $10 \mathrm{~V}$ cathode drop voltage) which renders a sputter yield of $10^{-4}$ atoms per ion. With these numbers we arrive at a sputter erosion rate of about $7 \times 10^{-7} \mathrm{~g} / \mathrm{s}$. For different projectile ions the sputter yield is of the same order. For copper electrodes the sputter yields are higher by two orders of magnitude. For the ArW-system we can expect sputter rates of about $10^{-7}-10^{-8} \mathrm{~g} / \mathrm{C}$

\subsection{Evaporation of electrode material}

Power densities dissipated in the cathode arc roots up to several $10^{6} \mathrm{~W} / \mathrm{m}^{2}$ have been observed. As a consequence strong local heating and formation of hot spots at the cathode surface is reported by many authors. To meet the requirements of sufficient electron emission at the cathode, temperatures above the boiling point of the cathode material can be necessary depending on the work function of the metal. Fig. 2 shows the evaporation rate of tungsten in the arc root.

As we will show later the temperature of the tungsten in the arc spot area derived from the coupled current and energy balance equation is in the range of $4000 \mathrm{~K}$. From Fig. 2 we see that the erosion rate by evaporation at this temperature is $5 \times 10^{-3} \mathrm{~g} / \mathrm{cm}^{2} \mathrm{~s}$, it exceeds the sputter rate by orders of magnitude. In addition there will occure vapor jets and droplet formation (see $/ 2 /$ ). The latter effect can contribute considerably to electrode erosion. 


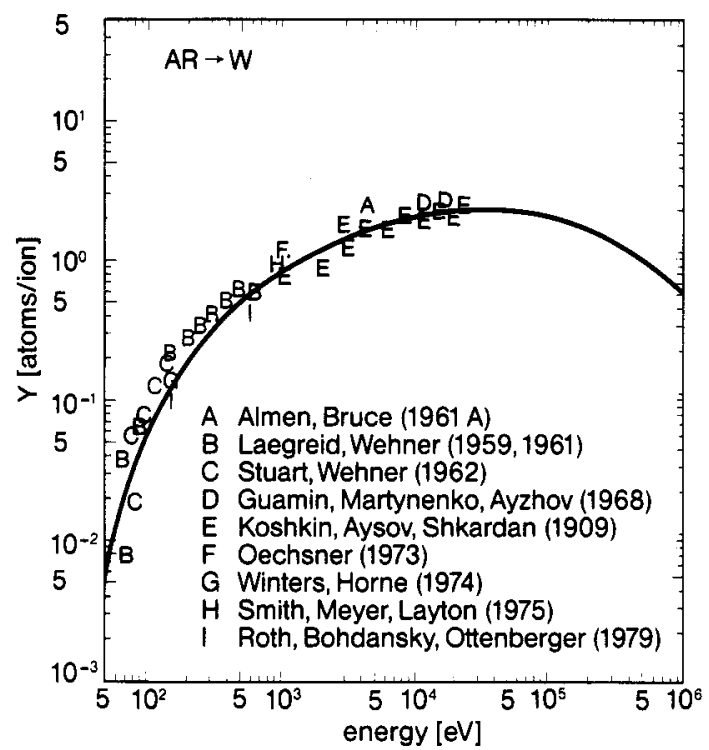

Fig. 1: Sputter yield for tungsten by $\mathrm{Ar}^{+}$versus projectile energy /3/

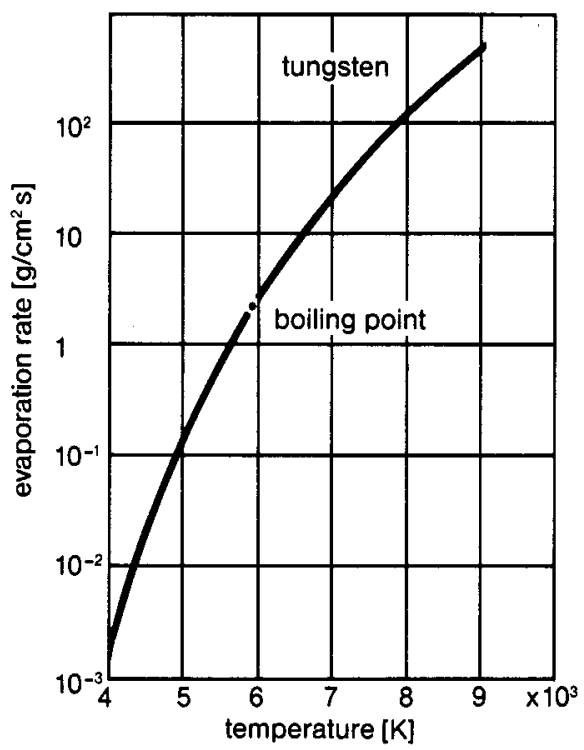

Fig. 2: Evaporation rate of tungsten versus temperature according to $/ 4 /$

\section{POWER BALANCE CONSIDERATIONS AT THE PLASMA-ELECTRODE INTERFACE}

The main parameters which determine electrode erosion are current density and temperature at the electrode surface. In many practical cases the current density is approximatively known from global experimental data. Then the temperature of the electrode surface and in turn the erosion rate in the roots of the arc can be calculated from the coupled power and current balance equations including an adequate model for the charge carrier emission from the cathode material. Calculations of this kind have been performed for various materials $(/ 4 /, / 5 /)$. In the following we apply a model for the arc roots of cathodic electrodes. For a single root at the cathode surface the power balance can be written as follows:

a) power dissipated into the cathode per unit surface:

$$
\begin{array}{ll}
\mathrm{J}_{\mathrm{i}} \cdot \mathrm{V}_{\mathrm{c}} & \text { power gained by the ions in the cathode voltage drop } \\
& \mathrm{J}_{\mathrm{j}}=\text { ion current density } 10^{5} \mathrm{~A} / \mathrm{mm} \\
& \mathrm{V}_{\mathrm{c}}=\text { cathode full voltage } 10 \mathrm{~V}
\end{array}
$$

$\mathrm{J}_{\mathrm{i}}\left(\mathrm{V}_{\mathrm{i}}-\varnothing\right) \quad$ power released to the cathode surface by recombination of the ions $\mathrm{V}_{\mathrm{i}}=15.7 \mathrm{eV}$ for argon ionization energy

$\varnothing^{1}=2.91 \mathrm{~V}$ work function for thoriated tungsten

$\mathrm{J}_{\mathrm{i}} \cdot 5 / 2 \mathrm{kT}_{\mathrm{i}} / \mathrm{e} \quad$ enthalpy of the ions $\left(\mathrm{hT}_{\mathrm{i}}=2 \mathrm{eV}\right)$

b) power released from the electrode per unit surface by various cooling mechanisms:

$$
\begin{array}{ll}
\mathrm{J}_{\mathrm{e}} \cdot \varnothing & \begin{array}{l}
\text { cooling by emission of electron current } \\
\text { density } \mathrm{j}_{\mathrm{e}}
\end{array} \\
\mathrm{q}_{\mathrm{c}} & \text { cooling by conduction (heatflux } \mathrm{q}_{\mathrm{c}} \text { ) } \\
\mathrm{q}_{\mathrm{v}} & \text { cooling by evaporation of electrode material } \\
\mathrm{q}_{\mathrm{r}}=\mathrm{T}^{4} & \text { radiation cooling }
\end{array}
$$

$\mathrm{q}_{\mathrm{v}}$ and $\mathrm{q}_{\mathrm{r}}$ are plotted in Fig. 3 versus temperature for tungsten. 


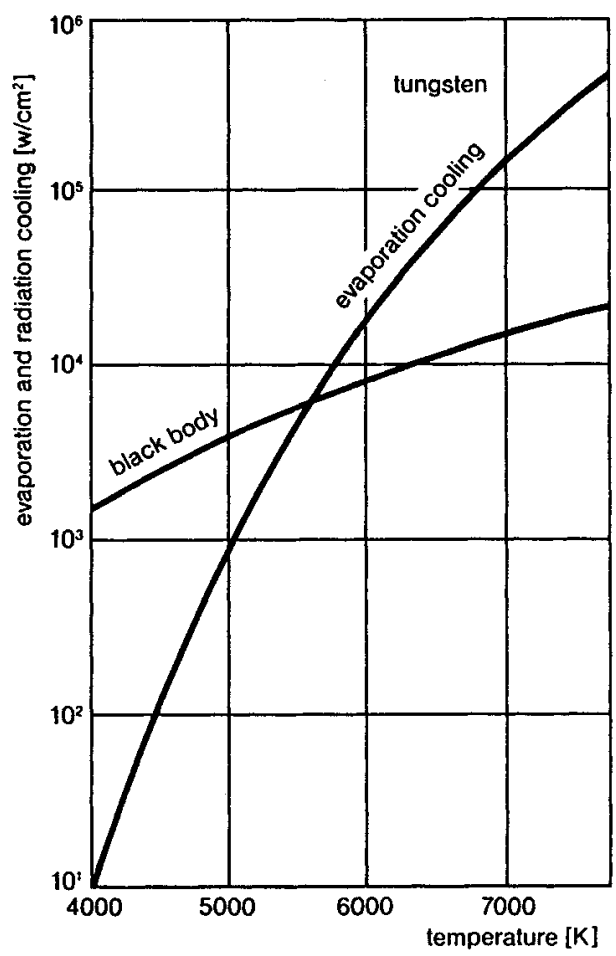

Fig. 3: Evaporation and radiation cooling versus temperature

Inspection of the individual contributions shows, that the main heating mechanism is the recombination of ions at the surface whereas the main bulk of dissipated power is cooled away by emissions of electrons.

Fig. 4 and 5 show the individual contribution as function of the current density.
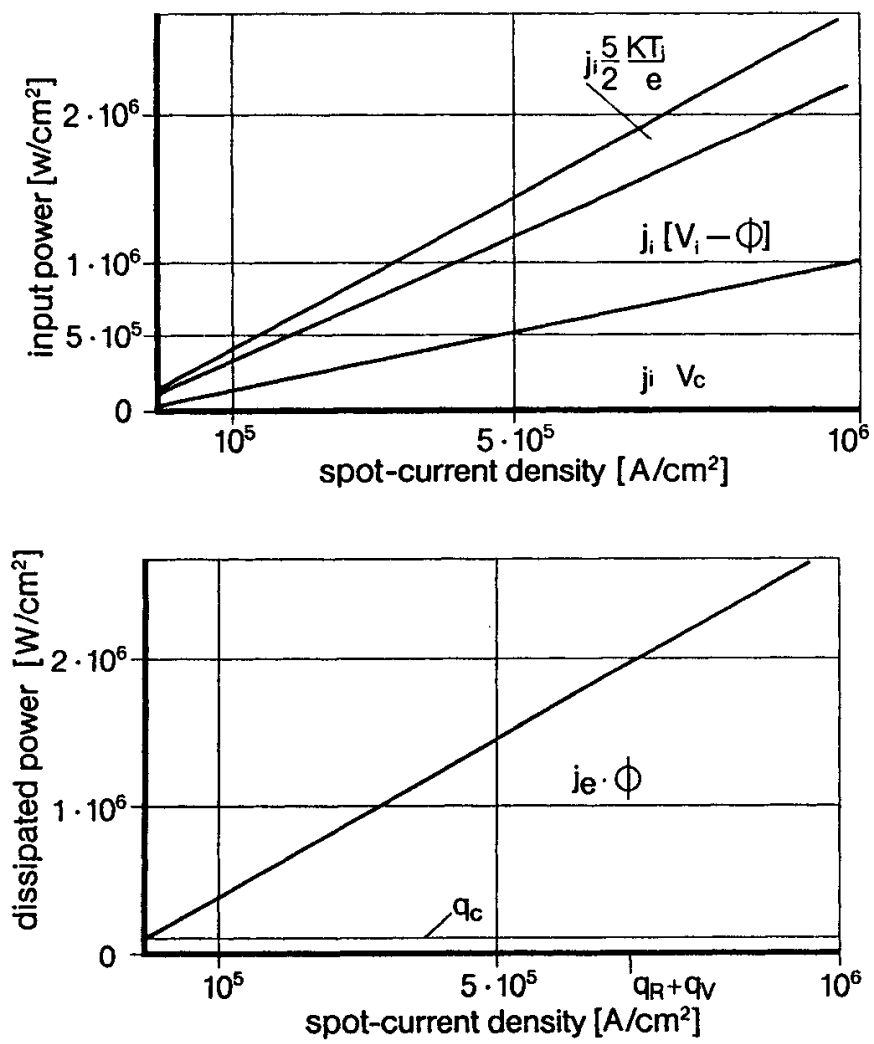

Fig. 4: Contribution of various heating mechanisms to the power transferred to the cathode spot
Fig. 5: Power removed from the cathode spot by various cooling mechanisms 
The erosion rate in the footprint of the arc root (cathode spot) is via the evaporation rate strongly dependent on the spot temperature, which is mainly determined by the current density and the electron emission properties of the electrode material. The numerical analysis is plotted in Fig. 6.

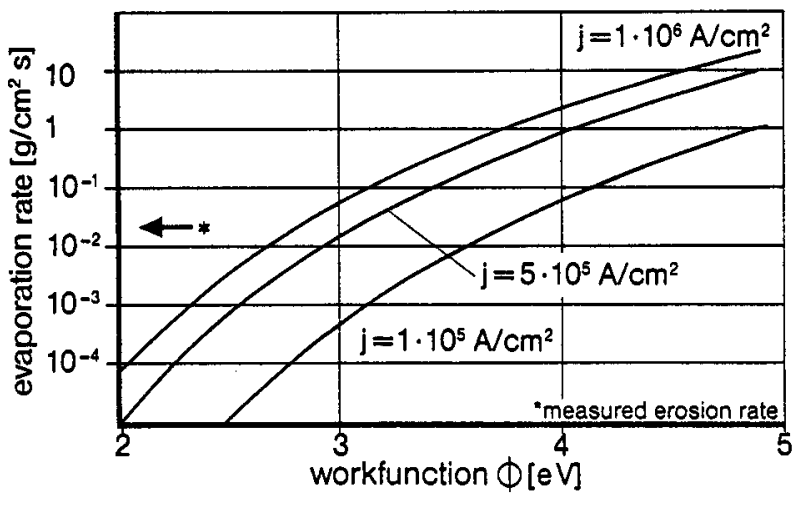

Fig. 6: Evaporation rate as function of current density and work function of the electrode material for a tungsten cathode

\section{SUMMARY}

A comparison of various erosion mechanisms at tungsten cathode during operation in high power arcs shows that melting and evaporation of the cathode is the main erosion process. A model calculation renders that a local temperature of the arc root of about $4000 \mathrm{~K}$ is nessecary for sufficient thermionic emission of electrons. $($ see $/ 6 /)$.

Though crude, the model gives wear rates quite close to those measured in high power arcs

\section{REFERENCES}

/1/ Ecker, G.

"Electrode Components of the Arc Discharge", Ergebnisse der exakten Naturwissenschaften, Band 23 (1961)

12/ Daalder, J.E.

J. Phys. B, Apl. Phys. $\underline{8}$ (1975), 1647

/3/ Matsunami, N., Y. Yamamura, N. Itoh, H. Tawara, T. Kamamura

Report IPPJ-AM-52 Nagoya (1987)

/4/ Cobine, J.D., Burger, E.E.

J. Appl. Phys. $\underline{26}$ (1955), 895

/5/ Salzberg, L.F.

"Theoretical and experimental investigation of Arc-Plasma-

Generation Technology" Part II, Report ASD-TDR-62-729 (1963)

16/ Fey, M.G., Mc Donald, J.

"Electrode Erosion in Electrical Arc Heaters", AICHE Symp. Series 186, Vol. 75, 37 